\section{$\angle$ Research Square \\ Preprints are preliminary reports that have not undergone peer review. \\ They should not be considered conclusive, used to inform clinical practice, or referenced by the media as validated information.}

\title{
Association Between Maternal Exposure to Indoor Air Pollution and Offspring Congenital Heart Disease: A Multi-Hospital Case-Control Study in East China
}

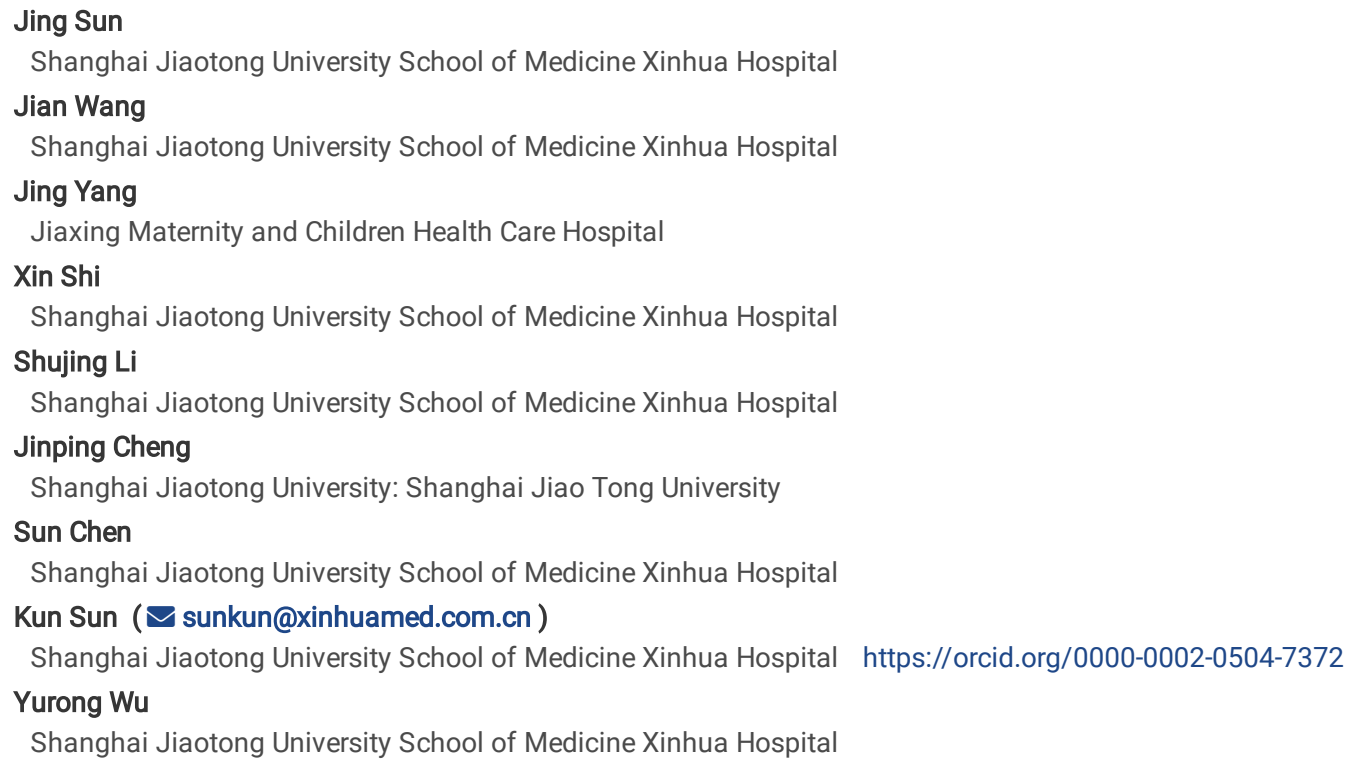




\section{Abstract}

Background: Previous research has suggested an association between maternal exposure to ambient air pollutants and the risk of congenital heart defects (CHDs). However, the effect of individual prenatal exposure to indoor air pollutants on CHD occurrence has not been reported.

Methods: We carried out a hospital-based case-control study to investigate the association between personal air pollution exposure during pregnancy and the risk of CHDs in offspring. A total of 32 cases and 74 controls were included in this study from two hospitals in East China. We investigated maternal and residential environmental characteristics using a questionnaire and obtained personal indoor air samples to assess particulate matter (PM) and volatile organic compounds (VOCs) from 22-30 gestational weeks; formaldehyde, benzene, toluene, xylene, total VOCs (TVOCs), PM 10 , and PM 2.5 were assessed. Logistic regression was performed to assess associations and interactions among individual indoor air pollutants and CHDs after adjusting for confounders. The potential residential environmental factors affecting the risks of indoor air pollutants on CHDs were also assessed.

Results: Median TVOC (0.430 vs. $\left.0.005 \mathrm{mg} / \mathrm{m}^{3}, \mathrm{P}<0.001\right), \mathrm{PM}_{2.5}\left(12.00\right.$ vs. $\left.8.00 \mu \mathrm{g} / \mathrm{m}^{3}, \mathrm{P}=0.037\right)$ and $\mathrm{PM} 10\left(13.50 \mathrm{vs} .8 .00 \mu \mathrm{g} / \mathrm{m}^{3}, \mathrm{P}=0.028\right)$ exposure levels in cases were significantly higher than those in controls. In a regression model adjusted for confounders, exposure to high levels of indoor TVOCs, $\mathrm{PM} \mathrm{M}_{2.5}$ and $\mathrm{PM}_{10}$ during pregnancy was associated with risks for $\mathrm{CHDs}$ and the occurrence of some major CHD subtypes in offspring. These risk effects were enhanced among pregnant woman living in a newly renovated house or near heavy-traffic roads but were mitigated by household usage of smoke ventilators when cooking. We observed a positive interaction of maternal exposure to TVOCs and $\mathrm{PM}_{2.5}$ in regard to the risk for CHDs.

Conclusions: Maternal exposure to indoor VOCs and PMs may increase the risk of giving birth to foetuses with CHDs.

\section{Introduction}

Congenital heart disease (CHD) is the most common congenital anomaly and is also a leading cause of infant death[1,2]. There are a number of common factors that affect CHD, including the protective effect of periconceptional folic acid supplementation[3] and risk factors such as advanced maternal age[4], low socioeconomic status[5], maternal diabetes mellitus[6], and maternal smoking and alcohol consumption[7]. An increasing amount of epidemiologic evidence suggests associations between maternal exposure to ambient air pollution and cardiovascular malformations among the offspring[8-11]. With increases in urbanization and improvements in living standards in developed eastern China, people's living environments and lifestyles have undergone significant changes, which may lead to the emergence of novel risk factors for CHDs in this population.

The public is paying great attention to indoor air quality due to the elevated indoor chemical concentrations and the fact that the majority of most people's time is spent in indoor environments. Exposure to indoor air pollution has been linked to cardiovascular[12] and pulmonary[13] effects. Individuals are exposed to various indoor pollutants, including both outdoor and indoor-specific sources, such as decoration materials and pollutants associated with activities such as cooking and cleaning, which can emit particulate matter (PM) and volatile organic compounds (VOCs)[14-16]. VOCs such as formaldehyde, benzene, toluene, xylene (BTX), and total VOCs (TVOCs), released mainly from paints and adhesives used in building and decorative materials, are known to result in adverse health outcomes[17]. PM less than 10 and 2.5 microns in diameter $\left(\mathrm{PM}_{10}\right.$ and $\left.\mathrm{PM}_{2.5}\right)$ can penetrate deep into the lungs and enter the bloodstream; thus, epidemiological evidence suggests that exposure to $\mathrm{PM}_{10}$ during the first trimester of gestation may increase the risk of $\mathrm{CHDs}$ [18].

Pregnant women and their foetuses are at higher risk than the normal population, as women tend to spend more time indoors during pregnancy and are more susceptible to environmental toxicants. Although rapidly growing epidemiologic literature has reported associations between atmospheric pollutants and adverse pregnancy events $[8,10,19]$, there are still limited data on the link between prenatal exposure to indoor air pollutants and CHD. Cardiac development is vulnerable to various physical and chemical factors that can lead to heart developmental abnormalities within the first 8 weeks of gestation. Research has suggested that the risk for CHD in offspring is significantly associated with maternal periconceptional housing renovation exposure, which is a newly recognized source of indoor environmental pollution[20]. Although it is essential to study the effects of exposure to indoor air pollutants in early pregnancy on cardiac development, objective evidence seems to be difficult to acquire. The reason might be the large amount of work required for field investigations, the low incidence of $\mathrm{CHD}$ in the pregnant population and the differences in individual dwelling environments. We designed this hospital-based case-control study to explore the relationship between indoor air quality during pregnancy and CHD in offspring. This pilot study could provide useful clues regarding whether indoor air pollutant exposure is associated with the occurrence of CHDs. The potential factors affecting the level of indoor air pollutant exposure and pollutant interactions with respect to CHDs were also assessed.

\section{Materials And Methods}

Study population and subjects

We conducted a hospital-based case-control study from May 2017 to October 2018 at two perinatal medical centres in East China (Shanghai Xinhua Hospital and Jiaxing Maternity and Child Health Care Hospital). These two centres are qualified as regional prenatal diagnosis centres with high-level ultrasound technology for the detection of foetal defects[21]. The study population was recruited from the population of pregnant women undergoing foetal echocardiography in the Department of Foetal Echocardiography in these two centres. Mothers receiving treatment in the hospital's obstetrics department are referred to the Foetal Echocardiography Unit if a CHD is suspected after an obstetric ultrasound examination. The inclusion criteria for the case group were (1) singleton pregnancy, (2) gestational age between 22 and 30 weeks at the time of the prenatal diagnosis, (3) foetus diagnosed with a defined isolated CHD, and (4) all foetal heart defects and malformations were confirmed after birth or abortion. Infants who were stillborn with CHD (including miscarriages and elective pregnancy terminations resulting from CHD) were eligible for inclusion if the diagnosis had been made prenatally. The controls, recruited from the same hospital during the same study period as the cases with a case-control ratio of 1:2, had no more than a two-week difference in gestational age from their 
matched case. Infants in the control group were defined as foetuses without CHD or other congenital malformations. Both case and control foetuses with chromosomal or other genetic syndromes diagnosed after referral to the clinical genetics service were excluded from our study. $\mathrm{CHD}$ cases that were associated with other congenital extracardiac defects were also ruled out.

All live births in the CHD case and control groups underwent complete neonatal echocardiography by paediatric cardiologists after delivery. Stillbirth and abortion cases were confirmed by autopsy or reviewed by an expert group composed of 5 national specialists from the fields of ultrasound, paediatrics, obstetrics and pathology to ensure the accuracy of the final diagnosis.

The recruited sample included 50 cases and 90 controls, including 9 cases and 15 controls who refused to participate or were lost to follow-up (Fig. 1). Five cases with a genetic syndrome and 5 cases with extracardiac defects were excluded, leaving 31 cases. In total, 75 infants were live born with diagnoses confirmed by echocardiogram, and one infant in the control group was diagnosed with pulmonary stenosis and reclassified into the case group. Therefore, a total of 32 cases and 74 controls were finally available for analysis in our research.

Moreover, all CHD cases were classified into subtypes based on anatomic malformation as previously proposed[22]. As multiple anatomical abnormalities may coexist in a single case, these groupings were not mutually exclusive, and overlap may exist. The subtypes were described as follows: (i) septal defects ( $n=16$ ), including ventricular septal defects, atrial septal defects and endocardial cushion defects; (ii) conotruncal defects ( $n=12)$, including tetralogy of Fallot, common truncus, transposition of the great arteries and double outlet right ventricle; (iii) right-sided obstruction ( $n=12$ ), including pulmonary valve stenosis, pulmonary artery/valve atresia and right ventricular hypoplasia; (iv) left-sided obstruction $(n=6)$, including coarctation of the aorta and left ventricular hypoplasia; and $(v)$ other cardiac structural abnormalities $(n=4)$, including single ventricle and anomalous pulmonary venous return.

Information collection

Trained researchers investigated the prenatal characteristics of the mothers using questionnaires on sociodemographics, reproductive history and periconceptional health status, including maternal and paternal age, maternal and paternal education level, maternal residence area, parity, family history of CHDs, and perinatal diseases (i.e., diabetes), maternal smoking, maternal alcohol consumption, and the use of folic acid and multivitamin supplements.

Additionally, information on residential environmental factors, including time spent indoors each day during the first trimester of pregnancy, maternal exposure to indoor renovations, ventilation time in newly renovated house, decorative materials in dwelling place, exposure to environmental pollutants around the residence, smoke ventilator usage when cooking, second-hand smoke exposure (paternal smoker or other nearby smokers) and exposure to household chemical products, was also obtained from self-reported questionnaires.

Indoor environmental field investigation and air pollutant measurements during pregnancy

Participants will undergo a field investigation within two weeks after signing the informed consent form and finishing the designated questionnaires. The number of gestational weeks at the time of the field investigation was recorded. This study was conducted in residential dwellings in Shanghai City and its ambient area from June 2017 to November 2018. Dwelling-related self-report questionnaires were verified by field survey. Concentrations of formaldehyde, BTX, TVOCs, and PM in households were monitored.

Room doors and windows were kept closed for 12 hours before the sampling process. We chose the living room, where people spend the most time, as the sampling area for health risk assessment among pregnant women. The samplers were placed in the middle of the sampled rooms at a height of $1.5 \mathrm{~m}$ above the floor and $1 \mathrm{~m}$ away from walls simulating the breathing zone. Indoor temperature and relative humidity were recorded when the samples were obtained.

VOCs were collected by active samplers (Tenax-TA, SUPELCO, USA) to a personal pump (DDY-1.5, Xingyu, China) for 20 min at a speed of 5 L/min; VOCs were then analysed by means of gas chromatography with flame ionization detection (GC-FID). The quantification of target VOCs (BTX) was accomplished by using multipoint external standard curves. The total quantified VOCs were included for TVOC concentration analysis.

Formaldehyde was sampled at a rate of $0.5 \mathrm{~L} / \mathrm{min}$ for $20 \mathrm{~min}$ using an air sampling pump and analysed by the 3-methyl-2-benzonthiazolinone hydrazine (MBTH) method with a UV-VIS spectrophotometer using an absorption wavelength of $630 \mathrm{~nm}$ (WFJ7200, Shanghai Unico Instrument Co., Ltd., Shanghai, China). More information related to the sampling and analytical methods are detailed in the Chinese National Standard GB/T $18883-2002$.

The levels of $\mathrm{PM}_{2.5}$ and $\mathrm{PM}_{10}$ were determined using a DUST-TRAK Aerosol Monitor (Model 8520, TSI Corporation, Shoreview, USA). Measurements were taken every minute for $30 \mathrm{~min}$, and the averages were taken to represent the $\mathrm{PM}_{2.5}$ and $\mathrm{PM}_{10}$ at the sampling area.

Method detection limits (MDLs) were $0.01 \mathrm{mg} / \mathrm{m}^{3}$ for BTX, formaldehyde and TVOC concentrations and $1.0 \mu \mathrm{g} / \mathrm{m}^{3}$ for $\mathrm{PM}_{2.5}$ and PM $10.0 \mathrm{Observations} \mathrm{below}$ the MDL were replaced with half the detection limit for statistical analysis.

Statistical analysis

Statistical analyses were performed using SPSS software (version 19.0; SPSS, Inc. IBM, Chicago, IL USA). Data are presented as the mean (standard deviation, SD), median (interquartile) or number (\%) as appropriate. Differences between groups were assessed with t-tests (for normally distributed variables), MannWhitney U-tests (for variables without a normal distribution) and chi-square tests (for categorical variables).

Bivariate analysis was first conducted for each potential CHD risk factor, including sociodemographic, reproductive history and periconceptional health status factors as well as residential environmental factors. 
Because of the skewed distribution of indoor air pollutant concentrations, they were categorized into low, moderate and high levels based on tertile distribution among controls. The associations between indoor air pollutant exposure levels and risks of CHDs were assessed by calculating the crude odds ratio (COR) and its $95 \%$ confidence interval $(\mathrm{Cl})$ using univariate logistic regression for each pollutant separately. In addition, correlations between the pollutant concentrations were assessed and checked for collinearity by Spearman rank correlation coefficients. Single-pollutant adjusted odds ratios (AORs) were adjusted for potential confounding effects using multivariate logistic regression. We selected covariate factors on the basis of the results of the bivariate analysis; variables with a $\mathrm{P}$ value less than 0.05 were entered into multivariable logistic regression. Due to the limited number of cases in the $\mathrm{CHD}$ subgroups, we recategorized TVOC, formaldehyde and $\mathrm{PM}_{2.5}$ exposure levels as "low" (1st and 2nd tertiles) and "high" (3rd tertile). These binary variables were used to estimate AORs to show the risk for CHD subtypes.

To further clarify whether residential environmental factors affect the risk of CHD at different pollutant exposure levels, factors including indoor renovations, residential surroundings, and smoke ventilator usage were stratified into their respective categories, in which the AOR for CHDs among mothers exposed to low-level pollutants was compared with those exposed to high-level pollutants.

A potentially relevant interaction between indoor air pollutants and CHD risk was evaluated by measures of effect modification on both additive and multiplicative scales. TVOCs, formaldehyde and $\mathrm{PM}_{2.5}$ were categorized as mentioned previously ("low" for the 1st and 2nd tertiles, "high" for the 3rd tertile). The effects were analysed for low TVOCs with low PM 2.5 , high TVOCs with low $\mathrm{PM}_{2.5}$, low TVOCs with high PM 2.5 , and high TVOCs with low PM 2.5 . Expected ORs in the multiplicative model were calculated as the product of the main effects. Relative excess risk due to interaction (RERI) was used to evaluate additive interaction, which was calculated for binary variables as $\left.R E R\right|_{I R R}=I R R_{11}-I R R_{10}-I R R_{01}+1$ [23]. We assessed the presence of interactions on the additive scale by using the RERI and the attributable proportion (AP) by using the algorithm of Andersson et al[24]. If the $95 \% \mathrm{Cl}$ of RERI and AP does not contain 0 , then there is an additive interaction; if the $\mathrm{P}$ value of the cross-product term in the logistic model is $<0.05$, then there is multiplication interaction[25].

PASS v.19 (NCSS, LLC Kaysville, UT USA) was used to calculate the sample size. We assumed a TVOC high-level-exposure rate of $40 \%$ in the control group, referencing the reported rate of indoor VOCs in China exceeding the standard rate of $20 \sim 60 \%[26]$. The total sample size was 96 (64 controls and 32 cases), which was thought to be required to achieve $80 \%$ power for detecting different TVOC exposures between the groups with an alpha error of 0.05 .

\section{Results}

The maternal sociodemographic characteristics, reproductive history and periconceptional health status of the study population are listed in Table 1. Both parental age and education level were significantly different between the case and control groups. No family history of CHD was observed among the study subjects. 
Table 1

Basic characteristics (sociodemographics, reproductive history, and periconceptional health status) of the study subjects

\begin{tabular}{|c|c|c|c|}
\hline \multirow[t]{2}{*}{ Characteristics } & $\begin{array}{l}\text { Controls } \\
(\mathrm{N}=72)\end{array}$ & $\begin{array}{l}\text { Cases } \\
(\mathrm{N}=34)\end{array}$ & \multirow[t]{2}{*}{ p Value* } \\
\hline & $\mathrm{n}(\%)$ & $\mathrm{n}(\%)$ & \\
\hline \multicolumn{4}{|l|}{ Maternal age (years) } \\
\hline$<25$ & $0(0)$ & $4(11.8)$ & 0.01 \\
\hline $25-29$ & $18(25)$ & $12(35.3)$ & \\
\hline $30-34$ & $40(55.6)$ & $12(35.3)$ & \\
\hline $35+$ & $14(19.4)$ & $16(17.9)$ & \\
\hline \multicolumn{4}{|l|}{ Paternal age (years) } \\
\hline$<25$ & $0(0)$ & $1(2.9)$ & 0.019 \\
\hline $25-29$ & $11(15.3)$ & $13(38.2)$ & \\
\hline $30-34$ & $36(50.0)$ & $10(29.4)$ & \\
\hline $35+$ & $25(34.7)$ & $10(29.4)$ & \\
\hline \multicolumn{4}{|l|}{ Maternal education level } \\
\hline Low (compulsory only) & $0(0)$ & $4(11.8)$ & 0.003 \\
\hline Medium (completed high school) & $7(9.7)$ & $7(20.6)$ & \\
\hline High (tertiary or higher) & $65(90.3)$ & $23(67.6)$ & \\
\hline \multicolumn{4}{|l|}{ Paternal education level } \\
\hline Low (compulsory only) & $2(2.8)$ & $5(14.7)$ & 0.023 \\
\hline Medium (completed high school) & $5(6.9)$ & $5(14.7)$ & \\
\hline High (tertiary or higher) & $65(90.3)$ & $24(70.6)$ & \\
\hline \multicolumn{4}{|l|}{ Residence } \\
\hline Urban & $69(95.8)$ & $32(94.1)$ & 0.655 \\
\hline Rural & $3(4.2)$ & $2(5.9)$ & \\
\hline \multicolumn{4}{|l|}{ Parity } \\
\hline Multiparous & $27(37.5)$ & $12(35.3)$ & 0.829 \\
\hline Primiparous & $45(62.5)$ & $22(64.7)$ & \\
\hline \multicolumn{4}{|l|}{ Folic acid supplementation } \\
\hline Never & $11(15.3)$ & $5(14.7)$ & 0.997 \\
\hline Occasionally/irregularly & $17(23.6)$ & $8(23.5)$ & \\
\hline Frequently/regularly & $44(61.1)$ & $21(61.8)$ & \\
\hline \multicolumn{4}{|l|}{ Multivitamin supplementation } \\
\hline Never & $29(40.3)$ & $19(55.9)$ & 0.277 \\
\hline Occasionally/irregularly & $11(15.3)$ & $5(14.7)$ & \\
\hline Frequently/regularly & $32(44.4)$ & $10(29.4)$ & \\
\hline \multicolumn{4}{|l|}{ Diabetes } \\
\hline No & $65(90.3)$ & $29(85.3)$ & 0.669 \\
\hline Yes & $7(9.7)$ & $5(14.7)$ & \\
\hline \multicolumn{4}{|l|}{ Maternal alcohol consumption } \\
\hline No & $54(75)$ & $26(76.5)$ & 0.787 \\
\hline Occasionally/irregularly & $17(23.6)$ & $8(23.5)$ & \\
\hline
\end{tabular}

*P value was calculated with chi-square or Fisher exact tests. 


\begin{tabular}{|llll|}
\hline Characteristics & $\begin{array}{l}\text { Controls } \\
(\mathbf{N}=\mathbf{7 2})\end{array}$ & $\begin{array}{l}\text { Cases } \\
(\mathbf{N}=\mathbf{3 4})\end{array}$ & p Value* \\
\cline { 2 - 3 } & $\mathbf{n}(\%)$ & $\mathbf{n}(\%)$ & \\
\hline Frequently/regularly & $1(1.4)$ & 0 & \\
\hline Maternal smoking & & & \\
\hline No & $70(97.2)$ & $33(97.1)$ & 1.000 \\
\hline Occasionally & $2(2.8)$ & $1(2.9)$ & \\
\hline *P value was calculated with chi-square or Fisher exact tests. \\
\hline
\end{tabular}


Table 2

Residential environmental characteristics of the study subjects

Characteristics

Controls $(\mathrm{N}=72)$

Cases $(\mathrm{N}=34)$

p Value

$\mathrm{n}(\%)$ or median (interquartile) $\mathrm{n}(\%)$ or median (interquartile)

Gestational weeks at the time of questionnaires (weeks) *

$24(6)$

$23.5(3)$

0.773

Gestational weeks at the time of field investigation (weeks) *

$26(6)$

$25(3)$

0.235

Time spent indoors each day during the first trimester (hours) *

$16(5)$

$14(5)$

0.637

House renovation and ventilation

No renovation

$52(72.2)$

$22(64.7)$

0.002

Living in a newly redecorated house with move-in interval $\mathbb{Z} 3$ months

$2(2.8)$

$8(23.5)$

Living in a newly redecorated house with move-in interval $\geq 3$ months

$18(25)$

$4(11.8)$

\section{Indoor floor decoration}

Wood-base flooring

34 (47.2)

$10(29.4)$

Marble and tile paving

$8(11.1)$

8 (23.5)

Carpet

$2(2.8)$

$2(5.9)$

Mix of various materials

$28(38.9)$

$14(41.2)$

Indoor wall decoration

Wallpaper

4 (5.6)

$2(5.9)$

0.961

Paint

$32(44.4)$

$16(47.1)$

Mix of various materials

$36(50)$

$15(47.1)$

Indoor furniture and ornaments

Wood-base furniture

34 (47.2)

$13(38.2)$

0.309

Wood and leather furniture

$13(18.1)$

$4(11.8)$

Mix of various materials

$25(34.7)$

$17(50)$

Second-hand smoke

$\begin{array}{lll}\text { Not exposed } & 43(59.7) & 22(64.7) \\ \text { Exposed } & 29(40.3) & 12(35.3)\end{array}$

Exposure to environmental pollutants nearby the residence

Cornfields and orchards

Chemical plant

Heavy-traffic road

Incineration plant

More than two facilities concomitantly

1 3

1

23

0

Special facilities combined

No

47 (65.3)

$13(38.2)$

0.005

Heavy traffic road

$23(31.9)$

$15(44.1)$

Other special facilities

$2(2.8)$

$6(17.6)$

Smoke ventilators usage when cooking

No

14 (19.4)

18 (52.9)

$\varangle 0.001$

Yes

$58(80.6)$

$16(47.1)$

Exposure to household chemical products

Pesticides

7

Disinfectants and sanitizers

0

1

1

*For abnormally distributed continuous variables, the median (interquartile) was used to describe the distribution, while the $\mathrm{P}$ values were calculated by the Mann-Whitney U-test. 


\begin{tabular}{|c|c|c|c|}
\hline \multirow[t]{2}{*}{ Characteristics } & Controls $(\mathrm{N}=72)$ & Cases $(\mathrm{N}=34)$ & p Value \\
\hline & n (\%) or median (interquartile) & n (\%) or median (interquartile) & \\
\hline Paints, dyes and glues & 1 & 0 & \\
\hline Household cleaning agents & 5 & 2 & \\
\hline \multicolumn{4}{|l|}{ Special chemicals combined } \\
\hline None & $52(72.2)$ & $27(79.4)$ & 0.75 \\
\hline One & $13(18.1)$ & $4(11.8)$ & \\
\hline Multiple & $7(9.7)$ & $3(8.8)$ & \\
\hline
\end{tabular}

Table 2 compares the two groups according to residential environmental characteristics. The two groups spent a similar amount of time indoors each day during the first trimester, with a median of more than 14 hours per day. Significant differences in proportions between the mothers from the case and control groups were detected with respect to maternal exposure to environmental pollutants near the residence, indoor renovations and ventilation time, and smoke ventilator usage when cooking. Eight case women (23.5\%) reported exposure to housing renovations with a moving-in interval of less than 3 months, while the same situation occurred in only $2.8 \%$ of the control group. A larger proportion of cases than controls lived in residences near heavily trafficked roads (44.1\% vs. $31.9 \%)$. The rate of ventilator use when cooking was much higher in the control group than in the case group ( $80.6 \%$ vs. $47.1 \%)$. There were no betweengroup differences found in decorative materials of dwelling place, exposure to household chemical products or exposure to second-hand smoke.

Median (interquartile) TVOC [0.430 (2.305) vs. 0.005 (0.250) mg/m³, P<0.001], $\mathrm{PM}_{2.5}\left[12.00\right.$ (8.25) vs. $\left.8.00(11.00) \mu \mathrm{g} / \mathrm{m}^{3}, \mathrm{P}=0.037\right]$ and $\mathrm{PM}$ 10 $[13.50(11.25)$ vs. $8.00(14.00) \mu \mathrm{g} / \mathrm{m}^{3}, \mathrm{P}=0.028$ ] levels in cases were significantly higher than those in controls (Table 3). Formaldehyde concentrations were found to exceed the Chinese indoor exposure limit in 6 cases (17.6\%) and 12 controls (16.7\%), despite no significant difference between the groups. The concentrations of BTX were detected at very low levels in both groups with a median (interquartile) close to zero. Although some studies suggested that temperature and humidity may affect indoor air pollutant concentrations[27], we did not find any difference in temperature or humidity between the two groups, and most of the subjects were recruited in spring or summer.

Table 4 shows the correlation analysis for these indoor air pollutants. The correlation coefficient between formaldehyde and other pollutants ranged from $0.26-0.45$ with statistical significance. BTX concentrations were closely related to each other with moderate correlations ranging from $0.52-0.72$ ( $P<0.001)$, suggesting that these three pollutants could have similar or common sources. $\mathrm{PM}_{2.5}$ and $\mathrm{PM}_{10}$ concentrations were highly correlated, with a coefficient of 0.97 $(P<0.001)$, indicating their common source of pollution. TVOCs, as the total concentrations of formaldehyde, BTX and other VOCs, showed no obvious correlations with PM. 
Table 3

Descriptive statistics of indoor air pollutants in the case and control groups ${ }^{a}$

\begin{tabular}{|c|c|c|c|c|c|c|c|c|c|c|}
\hline \multirow{2}{*}{$\begin{array}{l}\text { Indoor air } \\
\text { pollution }\end{array}$} & \multirow{2}{*}{$\begin{array}{l}\text { Reference } \\
\text { limit value } \\
\#\end{array}$} & \multicolumn{4}{|l|}{ Case } & \multicolumn{4}{|l|}{ Control } & \multirow{2}{*}{$\begin{array}{l}\mathrm{P} \\
\text { value* }\end{array}$} \\
\hline & & $\begin{array}{l}\text { Mean } \\
\pm \text { SD }\end{array}$ & $\begin{array}{l}\text { Median } \\
\text { (interquartile) }\end{array}$ & $\begin{array}{l}\text { Range } \\
\text { (min- } \\
\text { max) }\end{array}$ & $\begin{array}{l}\text { Number over } \\
\text { reference limit } \\
\text { (N/\%) }\end{array}$ & $\begin{array}{l}\text { Mean } \\
\pm S D\end{array}$ & $\begin{array}{l}\text { Median } \\
\text { (interquartile) }\end{array}$ & $\begin{array}{l}\text { Range } \\
\text { (min- } \\
\max )\end{array}$ & $\begin{array}{l}\text { Number } \\
\text { over } \\
\text { reference } \\
\text { limit (\%) }\end{array}$ & \\
\hline $\mathrm{PM}_{10}, \mu \mathrm{g} / \mathrm{m}^{3}$ & $150^{\mathrm{b}}$ & $\begin{array}{l}15.735 \\
\pm 9.202\end{array}$ & $\begin{array}{l}13.500 \\
(11.250)\end{array}$ & $\begin{array}{l}2.000- \\
38.000\end{array}$ & 0 & $\begin{array}{l}15.125 \\
\pm \\
17.671\end{array}$ & $\begin{array}{l}8.000 \\
(14.000)\end{array}$ & $\begin{array}{l}1.000- \\
84.000\end{array}$ & 0 & 0.028 \\
\hline $\mathrm{PM}_{2.5}, \mu \mathrm{g} / \mathrm{m}^{3}$ & $75^{c}$ & $\begin{array}{l}13.294 \\
\pm 7.677\end{array}$ & $\begin{array}{l}12.000 \\
(8.250)\end{array}$ & $\begin{array}{l}2.000- \\
32.000\end{array}$ & 0 & $\begin{array}{l}12.931 \\
\pm \\
14.831\end{array}$ & $\begin{array}{l}8.000 \\
(11.000)\end{array}$ & $\begin{array}{l}1.000- \\
73.000\end{array}$ & $6(8.3)$ & 0.037 \\
\hline $\begin{array}{l}\text { Benzene, } \\
\mathrm{mg} / \mathrm{m}^{3}\end{array}$ & $0.11^{b}$ & $\begin{array}{l}0.055 \\
\pm 0.190\end{array}$ & $0.005(0.000)$ & $\begin{array}{l}0.005- \\
1.000\end{array}$ & $3(8.8)$ & $\begin{array}{l}0.038 \\
\pm 0.148\end{array}$ & $0.005(0.000)$ & $\begin{array}{l}0.005- \\
1.000\end{array}$ & $4(5.6)$ & 0.535 \\
\hline $\begin{array}{l}\text { Toluene, } \\
\mathrm{mg} / \mathrm{m}^{3}\end{array}$ & $0.2^{\mathrm{b}}$ & $\begin{array}{l}0.066 \\
\pm 0.199\end{array}$ & $0.005(0.000)$ & $\begin{array}{l}0.005- \\
1.000\end{array}$ & $4(11.8)$ & $\begin{array}{l}0.034 \\
\pm 0.107\end{array}$ & $0.005(0.000)$ & $\begin{array}{l}0.005- \\
0.600\end{array}$ & $6(8.3)$ & 0.322 \\
\hline $\begin{array}{l}\text { Xylene, } \\
\mathrm{mg} / \mathrm{m}^{3}\end{array}$ & $0.2^{b}$ & $\begin{array}{l}0.066 \\
\pm 0.252\end{array}$ & $0.005(0.000)$ & $\begin{array}{l}0.005- \\
1.400\end{array}$ & $3(8.8)$ & $\begin{array}{l}0.039 \\
\pm 0.128\end{array}$ & $0.005(0.000)$ & $\begin{array}{l}0.005- \\
0.600\end{array}$ & $5(6.9)$ & 0.734 \\
\hline $\begin{array}{l}\text { Formaldehyde, } \\
\mathrm{mg} / \mathrm{m}^{3}\end{array}$ & $0.1^{\mathrm{b}}$ & $\begin{array}{l}0.078 \\
\pm 0.142\end{array}$ & $0.010(0.055)$ & $\begin{array}{l}0.005- \\
0.609\end{array}$ & $6(17.6)$ & $\begin{array}{l}0.077 \\
\pm 0.142\end{array}$ & $0.022(0.037)$ & $\begin{array}{l}0.005- \\
0.790\end{array}$ & $12(16.7)$ & 0.483 \\
\hline TVOC, mg/m³ & $0.6^{\mathrm{b}}$ & $\begin{array}{l}1.352 \\
\pm 1.768\end{array}$ & $0.430(2.305)$ & $\begin{array}{l}0.005- \\
7.027\end{array}$ & $20(58.8)$ & $\begin{array}{l}0.214 \\
\pm 0.389\end{array}$ & $0.005(0.250)$ & $\begin{array}{l}0.005- \\
1.850\end{array}$ & $4(5.6)$ & $\dot{0} 001$ \\
\hline $\begin{array}{l}\text { Temperature, } \\
{ }^{\circ} \mathrm{C}\end{array}$ & I & $\begin{array}{l}25.741 \\
\pm 4.642\end{array}$ & $\begin{array}{l}26.000 \\
(5.250)\end{array}$ & $\begin{array}{l}14.000- \\
34.000\end{array}$ & / & $\begin{array}{l}27.008 \\
\pm 3.562\end{array}$ & $\begin{array}{l}28.000 \\
(4.000)\end{array}$ & $\begin{array}{l}19.000- \\
34.000\end{array}$ & / & 0.186 \\
\hline $\begin{array}{l}\text { Relative } \\
\text { humidity, \% }\end{array}$ & I & $\begin{array}{l}44.319 \\
\pm \\
10.631\end{array}$ & $\begin{array}{l}40.500 \\
(15.250)\end{array}$ & $\begin{array}{l}27.000- \\
69.000\end{array}$ & / & $\begin{array}{l}47.193 \\
\pm 7.401\end{array}$ & $\begin{array}{l}47.500 \\
(9.750)\end{array}$ & $\begin{array}{l}30.000- \\
63.000\end{array}$ & / & 0.054 \\
\hline
\end{tabular}

b Indoor exposure limits were referenced from Chinese national GB/T $18883-2002$.

c Indoor $\mathrm{PM}_{2.5}$ exposure limit was referenced from Chinese national ambient air quality standard GB3095-2012.

* P value was calculated by Mann-Whitney U-test for nonnormally distributed continuous variables.

Table 4

Pearson correlation coefficients for indoor air pollution

\begin{tabular}{|c|c|c|c|c|c|c|c|}
\hline & $\mathrm{PM}_{10}$ & $\mathrm{PM}_{2.5}$ & Benzene & Toluene & Xylene & Formaldehyde & TVOC \\
\hline $\mathrm{PM}_{10}$ & 1.00 & & & & & & \\
\hline $\mathrm{PM}_{2.5}$ & $0.97 \star \star$ & 1.00 & & & & & \\
\hline Benzene & 0.17 & 0.15 & 1.00 & & & & \\
\hline Toluene & 0.04 & 0.02 & $0.72^{\star \star}$ & 1.00 & & & \\
\hline Xylene & 0.06 & 0.06 & $0.55^{\star \star}$ & $0.52^{\star *}$ & 1.00 & & \\
\hline Formaldehyde & $0.26^{\star \star}$ & $0.29 * \star$ & $0.48^{\star \star}$ & $0.25^{\star}$ & $0.45^{\star \star}$ & 1.00 & \\
\hline TVOC & 0.15 & 0.15 & 0.19 & $0.20 *$ & $0.29 \star \star$ & $0.26^{* *}$ & 1.00 \\
\hline
\end{tabular}

Associations between indoor air pollutant levels and CHDs were investigated using univariate and multivariable single-pollutant regression models. Multivariable models were adjusted for variables considered to be significantly different in bivariate analysis, including both parental age and education level, house renovation and ventilation, exposure to environmental pollutants near the residence, and smoke ventilator usage when cooking. Because BTX concentrations of the majority of subjects in both groups were below the MDLs or were not detected at all, we did not estimate ORs of BTX exposure levels in regression models due to the limited statistical power.

As shown in Table 5, a high level of TVOCs was associated with CHD in univariable analysis (COR 4.46, 95\% $\mathrm{Cl} 1.69-11.77$ ) and was enhanced with an elevated AOR of 5.72 (1.6-20.49). Compared with the low level of $\mathrm{PM}_{2.5}$, infants of mothers in the middle and high levels had higher odds for CHDs, with AORs of 11.98 (95\% Cl: $1.63-88.04)$ and 10.30 (95\% Cl: $1.51-70.16)$, respectively, despite the wide confidence intervals. Similar to its strong correlation with $\mathrm{PM}_{2.5}$, we found that $\mathrm{PM}_{10}$ exposure was similarly associated with CHDs, with a middle-level AOR of 17.59 (95\% Cl: 1.98-155.96) and a high-level AOR of 18.31 (95\% Cl: 2.14-156.41) vs. the low level. We did not find any association between formaldehyde exposure level and CHD risk.

Page 9/18 
Table 5

Associations between indoor air pollutant exposure levels and CHDs

\begin{tabular}{|c|c|c|c|c|}
\hline \multirow{2}{*}{$\begin{array}{l}\text { Indoor air pollutant } \\
\text { exposure levels }\end{array}$} & \multirow{2}{*}{$\begin{array}{l}\text { Controls } \\
\mathrm{N}(\%)\end{array}$} & \multirow{2}{*}{$\begin{array}{l}\text { Cases } \\
\mathrm{N}(\%)\end{array}$} & \multirow[t]{2}{*}{ COR } & \multirow[t]{2}{*}{$\mathrm{AOR}^{\mathrm{a}}$} \\
\hline & & & & \\
\hline \multicolumn{5}{|l|}{ TVOC $^{b}$} \\
\hline $\operatorname{Low}\left(\leq 0.005 \mathrm{mg} / \mathrm{m}^{3}\right)$ & $38(52.8)$ & $9(26.5)$ & Reference & Reference \\
\hline Middle $\left(0.006-0.24 \mathrm{mg} / \mathrm{m}^{3}\right)$ & $16(22.2)$ & $6(17.6)$ & $1.58(0.48-5.19)$ & $1.34(0.27-6.52)$ \\
\hline $\operatorname{High}\left(\geq 0.25 \mathrm{mg} / \mathrm{m}^{3}\right)$ & $18(25.0)$ & $19(55.9)$ & $4.46^{\star \star}(1.69-11.77)$ & $5.72^{\star \star}(1.6-20.49)$ \\
\hline \multicolumn{5}{|l|}{ Formaldehyde } \\
\hline Low $\left(<0.01 \mathrm{mg} / \mathrm{m}^{3}\right)$ & $24(33.3)$ & $18(52.9)$ & Reference & Reference \\
\hline Middle $\left(0.01-0.02 \mathrm{mg} / \mathrm{m}^{3}\right)$ & $24(33.3)$ & $5(14.7)$ & $0.39(0.12-1.22)$ & $0.62(0.15-2.65)$ \\
\hline High $\left(\geq 0.03 \mathrm{mg} / \mathrm{m}^{3}\right)$ & 24 (33.3) & $11(32.4)$ & $0.71(0.28-1.8)$ & $0.94(0.28-3.12)$ \\
\hline \multicolumn{5}{|l|}{$\mathrm{PM}_{2.5}$} \\
\hline Low $\left(<4 \mu \mathrm{g} / \mathrm{m}^{3}\right)$ & $26(36.2)$ & $3(8.8)$ & Reference & Reference \\
\hline Middle $\left(4-12.9 \mu \mathrm{g} / \mathrm{m}^{3}\right)$ & $23(31.9)$ & $17(50.0)$ & $6.41^{\star \star}(1.66-24.7)$ & $11.98^{\star}(1.63-88.04)$ \\
\hline $\operatorname{High}\left(\geq 13 \mu \mathrm{g} / \mathrm{m}^{3}\right)$ & $23(31.9)$ & $14(41.2)$ & $5.28 *(1.34-20.71)$ & $10.30 *(1.51-70.16)$ \\
\hline \multicolumn{5}{|l|}{$\mathrm{PM}_{10}$} \\
\hline $\operatorname{Low}\left(<5 \mu \mathrm{g} / \mathrm{m}^{3}\right)$ & $22(30.6)$ & $2(5.9)$ & Reference & Reference \\
\hline Middle $\left(5-13.9 \mu \mathrm{g} / \mathrm{m}^{3}\right)$ & 24 (33.3) & $15(44.1)$ & $6.87 *(1.41-33.54)$ & $17.59 * \star(1.98-155.96)$ \\
\hline $\operatorname{High}\left(\geq 14 \mu \mathrm{g} / \mathrm{m}^{3}\right)$ & $26(36.1)$ & $17(50.0)$ & $7.19 *(1.49-34.62)$ & $18.31^{\star \star}(2.14-156.41)$ \\
\hline \multicolumn{5}{|c|}{$\begin{array}{l}\text { a Adjusted for maternal and paternal age, maternal and paternal education level, house renovation and ventilation (category), exposure to environmental } \\
\text { pollutants near the residence (category), and smoke ventilator usage when cooking. }\end{array}$} \\
\hline \multicolumn{5}{|c|}{$\begin{array}{l}\text { b As the TVOC concentration was below the MDL in more than one-third of the control population, TVOC exposure levels were divided into low (equal or } \\
\text { lesser than the MDL value), middle (below the median detected value of the control distribution), and high (above the median detected value of the contro } \\
\text { distribution) groups. }\end{array}$} \\
\hline
\end{tabular}

Due to the limited number of participants in the CHD subgroups, further analysis was performed to compare the cases and controls when these pollutant exposure levels were dichotomized into two levels as described in the aforementioned methods section. The association with high TVOC levels was also present in the subgroups of septal defects and right-sided obstructions in the context of the recategorized low level [AOR 16.73 (95\% Cl: 2.25-124.65) and 10.68 (95\% Cl: $1.28-89.43$ ), respectively] but not in subgroup of conotruncal defects (Table 6). Other pollutants, including formaldehyde, $\mathrm{PM}_{2.5}$ and $\mathrm{PM}_{10}$, did not show any statistically significant association with CHD subtypes in the context of this recategorized binary exposure level.

We chose several residential-level environmental factors that were considered to be correlated with indoor air pollutant exposure, referring to the previous literature. Table 7 shows the effects of air pollutants on CHDs in offspring among all participants and stratified by house renovation, smoke ventilator usage, and exposure to environmental pollutants near the residence. Due to the limited sample size, recategorized binary exposure levels of pollutants were used to compare the $\mathrm{ORs}$ for $\mathrm{CHD}$ in different stratifications. 
Table 6

Effect of indoor air pollutant exposure levels on CHD subtypes. ${ }^{\text {a }}$

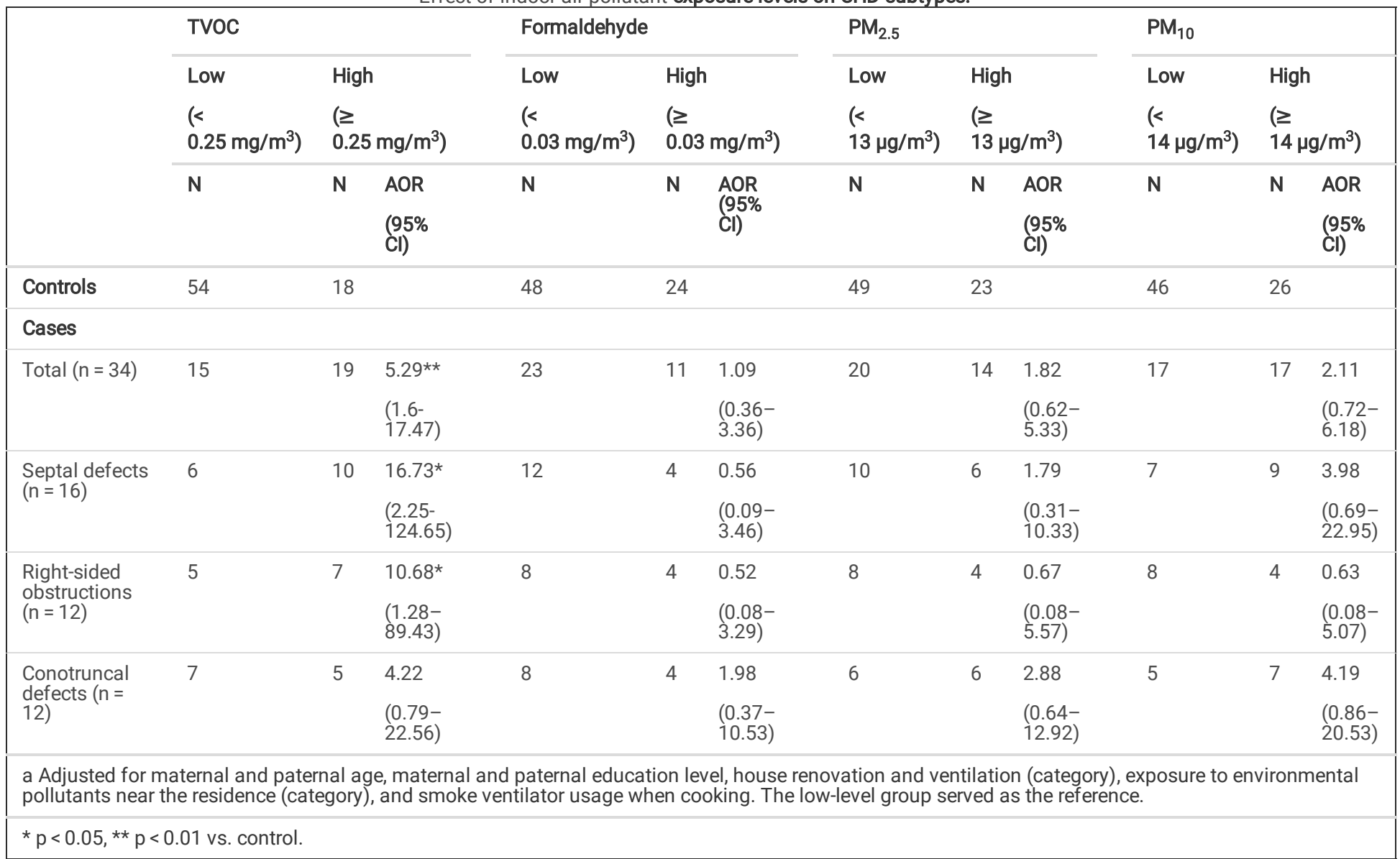


Table 7

Effect of the association of CHDs with indoor air pollutant exposure levels by stratified status of house renovation, smoke ventilator usage and exposu

\begin{tabular}{|c|c|c|c|c|c|c|c|c|c|}
\hline & \multicolumn{4}{|c|}{ Living in a newly renovated house } & \multicolumn{4}{|c|}{ Use of smoke ventilators when cooking } & \multirow{3}{*}{$\begin{array}{l}\text { Expo } \\
\text { Nont } \\
\mathrm{N}, \\
\text { cont। }\end{array}$} \\
\hline & \multicolumn{2}{|l|}{ No $(n=74)$} & \multicolumn{2}{|l|}{ Yes $(\mathrm{N}=32)$} & \multicolumn{2}{|l|}{ No $(n=32)$} & \multicolumn{2}{|l|}{ Yes $(N=74)$} & \\
\hline & $\begin{array}{l}\mathrm{N}, \\
\text { controls/cases }\end{array}$ & $\mathrm{AOR}^{\mathrm{a}}$ & $\begin{array}{l}\mathrm{N} \text {, } \\
\text { Controls/cases }\end{array}$ & $\mathrm{AOR}^{\mathrm{a}}$ & $\begin{array}{l}\mathrm{N}, \\
\text { controls/cases }\end{array}$ & $A O R^{b}$ & $\begin{array}{l}\mathrm{N}, \\
\text { controls/cases }\end{array}$ & $A O R^{b}$ & \\
\hline \multicolumn{10}{|l|}{ TVOC } \\
\hline $\begin{array}{l}\text { Low }(< \\
\left.0.25 \mathrm{mg} / \mathrm{m}^{3}\right)\end{array}$ & $39 / 12$ & Reference & $15 / 3$ & Reference & $12 / 7$ & Reference & $42 / 8$ & Reference & $37 / 5$ \\
\hline $\begin{array}{l}\text { High }(\geq \\
\left.0.25 \mathrm{mg} / \mathrm{m}^{3}\right)\end{array}$ & $13 / 10$ & $\begin{array}{l}2.68 \\
(0.66- \\
10.81)\end{array}$ & $5 / 9$ & $\begin{array}{l}32.13^{\star} \\
(1.48- \\
698.11)\end{array}$ & $2 / 11$ & $\begin{array}{l}13.1 \\
(0.73- \\
234.81)\end{array}$ & $16 / 8$ & $\begin{array}{l}4.44^{*} \\
(1.03- \\
19.18)\end{array}$ & $10 / 8$ \\
\hline \multicolumn{10}{|l|}{ Formaldehyde } \\
\hline $\begin{array}{l}\text { Low }(< \\
\left.0.03 \mathrm{mg} / \mathrm{m}^{3}\right)\end{array}$ & $35 / 14$ & Reference & $13 / 9$ & Reference & $9 / 12$ & $(0)$ & $39 / 11$ & Reference & $30 / 9$ \\
\hline $\begin{array}{l}\text { High }(\geq \\
\left.0.03 \mathrm{mg} / \mathrm{m}^{3}\right)\end{array}$ & $17 / 8$ & $\begin{array}{l}1.91 \\
(0.47- \\
7.82)\end{array}$ & $7 / 3$ & $\begin{array}{l}0.76 \\
(0.09- \\
6.8)\end{array}$ & $5 / 6$ & $\begin{array}{l}0.53 \\
(0.03- \\
8.49)\end{array}$ & $19 / 15$ & $\begin{array}{l}1(0.23- \\
4.43)\end{array}$ & $17 / 4$ \\
\hline \multicolumn{10}{|l|}{$\mathrm{PM}_{2.5}$} \\
\hline $\begin{array}{l}\text { Low }(< \\
\left.13 \mu \mathrm{g} / \mathrm{m}^{3}\right)\end{array}$ & $38 / 11$ & Reference & $11 / 9$ & Reference & $6 / 13$ & $(0)$ & $43 / 7$ & Reference & $29 / 1$ \\
\hline $\begin{array}{l}\text { High }(\geq \\
\left.13 \mu \mathrm{g} / \mathrm{m}^{3}\right)\end{array}$ & $14 / 11$ & $\begin{array}{l}2.55 \\
(0.68- \\
9.52)\end{array}$ & $9 / 3$ & $\begin{array}{l}1.01 \\
(0.14- \\
7.46)\end{array}$ & $8 / 5$ & $\begin{array}{l}0.16 \\
(0.01- \\
1.83)\end{array}$ & $15 / 9$ & $\begin{array}{l}1.01 \\
(0.14- \\
7.46)\end{array}$ & $18 / 3$ \\
\hline \multicolumn{10}{|l|}{$\mathrm{PM}_{10}$} \\
\hline $\begin{array}{l}\text { Low }(< \\
\left.14 \mu g / \mathrm{m}^{3}\right)\end{array}$ & $35 / 9$ & Reference & $11 / 8$ & Reference & $6 / 10$ & $(0)$ & $40 / 7$ & Reference & $27 / 9$ \\
\hline $\begin{array}{l}\operatorname{High}(\geq \\
\left.14 \mu \mathrm{g} / \mathrm{m}^{3}\right)\end{array}$ & $17 / 13$ & $\begin{array}{l}3.26 \\
(0.85- \\
12.47)\end{array}$ & $9 / 4$ & $\begin{array}{l}1.01 \\
(0.14- \\
7.46)\end{array}$ & $8 / 8$ & $\begin{array}{l}0.49 \\
(0.07- \\
3.52)\end{array}$ & $18 / 9$ & $\begin{array}{l}1.01 \\
(0.14- \\
7.46)\end{array}$ & $20 / 4$ \\
\hline
\end{tabular}

a Adjusted for maternal and paternal age, maternal and paternal education level, exposure to environmental pollutants near the residence (category), and sm

b Adjusted for maternal and paternal age, maternal and paternal education level, house renovation and ventilation (category), and exposure to environmental c Adjusted for maternal and paternal age, maternal and paternal education level, house renovation and ventilation (category), and smoke ventilator usage wh

The low-level group served as the reference.

$* p<0.05$ vs. control.

Among participants living in newly redecorated houses, high TVOC exposure was significantly associated with the risk of CHDs (AOR 32.13, 95\% Cl: $1.48-$ 698.11). The AOR of high TVOC for CHDs was estimated to be 4.44 (95\% Cl: 1.03-19.18) in houses using smoke ventilators when cooking, while the AOR value tended to be higher in houses without the use of smoke ventilators, but the difference was not statistically significant (AOR $13.1,95 \%$ Cl: $0.73-234.81, p$ $=0.08$ ). Associations of high $\mathrm{PM}_{2.5}$ and $\mathrm{PM}_{10}$ exposure levels with the risk of $\mathrm{CHDs}$ were found among participants living in residences near heavy-traffic roads (OR 9.16, 95\% Cl: 1.2-69.93, and OR $8.89,95 \%$ Cl: 1.14-69.6, respectively). Nevertheless, the CHD risk associated with air pollutants was not statistically significant among participants with no house renovation, no use of smoke ventilators or no exposure to environmental pollutants near the residence.

We analysed interactions between TVOC and $\mathrm{PM}_{2.5}$ in terms of pairwise combinations modifying the risk for CHDs (Table 8). We observed a joint association AOR of 6.77 (95\% Cl: 1.50-30.59) for high TVOCs with high $\mathrm{PM}_{2.5}$ compared with low TVOCs and low PM 2.5 . Moreover, there was a statistically significant multiplicative interaction between TVOCs and $\mathrm{PM}_{2.5}$ (AOR 4.03, 95\% Cl: 1.09-14.87, p = 0.036), suggesting that high TVOCs and high PM 2.5 may interact synergistically to increase the risk of CHDs. Although an RERI value of 2.46 was calculated in the additive model, probably indicating a positive interaction of TVOCs and $\mathrm{PM}_{2.5}$, this evidence was weak, as evidenced by the wide confidence interval crossing $0(95 \% \mathrm{Cl}:-7.01,11.93)$. 
Table 8

Interaction effects of exposure to TVOCs and $\mathrm{PM}_{2.5}$ on the risks of CHDs

\begin{tabular}{|c|c|c|c|}
\hline Exposure & $\mathrm{N}$, controls/cases & $\mathrm{AOR}^{\mathrm{a}}(95 \% \mathrm{Cl})$ & $p$ value \\
\hline \multicolumn{4}{|c|}{ TVOCs with $\mathrm{PM}_{2.5}$ (dichotomous) } \\
\hline Low TVOC and low $\mathrm{PM}_{2.5}$ & $38 / 11$ & Reference & \\
\hline High TVOC and low $\mathrm{PM}_{2.5}$ & $11 / 9$ & $4.2(0.82-21.65)$ & 0.086 \\
\hline Low TVOC and high $\mathrm{PM}_{2.5}$ & $16 / 4$ & $1.11(0.21-5.84)$ & 0.902 \\
\hline High TVOC and high $\mathrm{PM}_{2.5}$ & $7 / 10$ & $6.77(1.5-30.59)$ & 0.013 \\
\hline \multicolumn{2}{|l|}{ Cross-product for interaction } & $4.03(1.09-14.87)$ & 0.036 \\
\hline \multicolumn{2}{|l|}{ RERI on the additive scale } & $2.46(-7.01-11.93)$ & \\
\hline \multicolumn{2}{|l|}{ AP on the additive scale } & $0.36(-0.71-1.43)$ & \\
\hline
\end{tabular}

a Adjusted for maternal and paternal age, maternal and paternal education level, house renovation and ventilation (category), exposure to environmental pollutants near the residence (category), and smoke ventilator usage when cooking. The low-level group served as the reference.

\section{Discussion}

The current study aimed to determine the associations between CHDs in offspring and maternal exposure to indoor air pollution during pregnancy as measured in field-based investigations with a case-control design. Although this was a pilot study with a limited number of subjects, we observed that exposure to indoor TVOCs, $\mathrm{PM}_{2.5}$ and $\mathrm{PM}_{10}$ at high levels during pregnancy could result in increased risks for $\mathrm{CHDs}$ and the occurrence of some major subtypes in offspring, probably suggesting a potential dose-response relationship. Some household activities, including house renovation, smoke ventilator usage when cooking, and living near heavy-traffic roads, may affect the risks of CHDs associated with indoor air pollutants. Our results also suggested that maternal exposure to high levels of TVOCs in addition to high levels of $\mathrm{PM}_{2.5}$ may interact synergistically to increase the risk of $\mathrm{CHDs}$. These results provide support for the hypothesis that maternal exposure to indoor air pollution may have adverse effects on foetal cardiac development.

Reports linking environmental exposures to birth defects have steadily increased[11, 18,20$]$. However, the inability to routinely identify indoor environmental exposures during pregnancy, difficulty quantifying these exposures and maternal recall biases limit the ability to determine causal relationships. Indoor air pollution, compared to atmospheric pollution, is characterized by its complexity, ubiquity, and persistence, resulting in progressive and cumulative effects on health risk, especially among susceptible pregnant women[28]. Additionally, this research has suggested that most pregnant women spend more time indoors; thus, indoor air quality data are more important for analysing these effects.

VOCs and PM, which are considered to be major indoor air pollutants, have been widely studied for their adverse effects on cardiovascular[12] and pulmonary health[13] in the general population, but limited data among pregnant women and their foetuses have been reported. Some volatile organic solvents (e.g., trichloroethylene (TCE)), which may quickly evaporate and are preserved in the atmosphere, soil and ground water, are sources of indoor pollutant exposure by routes of inhalation, ingestion and skin contact[29]. A study indicated that TCE is likely to be a risk factor for CHD and reported a threefold increased CHD risk among mothers presumably exposed to TCE compared with the risk among non-exposed mothers[30]. Chang et al.[31] indicated that elevated exposure to TVOCs during the prenatal period may adversely influence early postnatal growth. A previous study[18] assessed the effects of ambient air pollutants on CHD and found that effect estimates of cardiac atrial septal defects for the first trimester were significantly increased with continuous and categorical $\mathrm{PM}_{10}$ exposure when comparing high exposures to low exposures. However, it was also reported that at the municipal level, exposure assessed by air pollution monitoring stations as a proxy for personal exposure results in smaller effect estimates than when using individual assessments of exposure[32]. To our knowledge, no prior study has evaluated the effect of indoor air pollution on foetal CHDs using individual maternal exposure data, and most studies were limited by self-reported or occupational exposure assessments.

Indoor air pollutant levels measured among our study participants were generally lower than those reported in previous studies. The mean value of formaldehyde was $0.078 \mathrm{mg} / \mathrm{m}^{3}$ for cases and $0.077 \mathrm{mg} / \mathrm{m}^{3}$ for controls in our study; these values were lower than the reported mean value of $0.175 \mathrm{mg} / \mathrm{m}^{3}$ in general houses in Harbin, China[33] and $81.6 \mu \mathrm{g} / \mathrm{m}^{3}$ in houses for pregnant women in Korea[31]. BTX concentrations in the majority houses were below the MDLs or were not detected at all. For total VOCs, a reported household mean value of $0.411 \mathrm{mg} / \mathrm{m}^{3}$ (ranging from $0.28-0.48 \mathrm{mg} / \mathrm{m}^{3}$ )[33] was close to our median concentration among cases $\left(0.430 \mathrm{mg} / \mathrm{m}^{3}\right)$ but far exceeded the concentration among controls $\left(0.005 \mathrm{mg} / \mathrm{m}^{3}\right)$. The median TVOC concentration among cases was also higher than the prenatal exposure value of $284.2 \mu \mathrm{g} / \mathrm{m}^{3}$ in Chang's research[31]. A study in Taipei, China recorded household indoor $\mathrm{PM}_{10}$ and $\mathrm{PM}_{2.5}$ mean concentrations of $41 \mu \mathrm{g} / \mathrm{m}^{3}$ (ranging from 7.8-99.4 $\mu \mathrm{g} / \mathrm{m}^{3}$ ) and $25.5 \mu \mathrm{g} / \mathrm{m}^{3}$ (ranging from $9.5-80.5 \mu \mathrm{g} / \mathrm{m}^{3}$ ), both of which were higher than those reported in our control participants (Table 5). According to the Chinese National Air Quality Standards GB/T 18883 and GB3095, the rates of exceeding the current reference value in both groups were below $20 \%$ for most indoor air pollutants except for TVOCs in the case group (58.8\%). 
Although the levels of maternal exposure to indoor air pollutants in our study were generally lower than those in previous studies conducted with the general population and below the Chinese national standard reference values, we did find results indicating that the risk of CHD occurrence in offspring might be associated with maternal high TVOC, $\mathrm{PM}_{2.5}$ and $\mathrm{PM}_{10}$ exposure levels, even at low concentrations. Compared with mothers with low TVOC levels (< $0.25 \mathrm{mg} / \mathrm{m}^{3}$ ), mothers exposed to high TVOC levels $\left(\geq 0.25 \mathrm{mg} / \mathrm{m}^{3}\right.$ ) had a 5.29 times higher risk for total CHDs (AOR 5.29, 95\% Cl: 1.6-17.47), 16.73 times higher risk for septal defects (AOR 16.73, 95\% Cl: 2.25-124.65) and 10.68 times higher risk for right-sided obstructions (AOR 10.68, 95\% Cl: 1.28-89.43) after adjusting for confounders. We found that $\mathrm{PM}_{2.5}$ concentrations above $13 \mu \mathrm{g} / \mathrm{m}^{3}$ and $\mathrm{PM}_{10}$ concentrations above $14 \mu \mathrm{g} / \mathrm{m}^{3}$ were associated with higher odds for total CHDs than their respective low concentrations levels. However, the target VOCs, such as formaldehyde and BTX, were not observed to be associated with CHD risk in our study, probably because newly presented or complicated organic compounds contributing to the TVOC concentration but not detected in our research played a role in $\mathrm{CHD}$ occurrence. Despite the imprecise effect estimates and undefined dose-effect relationships resulting from the small sample size, it is concerning that the current reference values in Chinese indoor air quality standards may lead to underestimation of the risks for CHDs associated with pollutants in pregnant women.

It is difficult to offer a plausible biological mechanism by which developmental toxicity and cardiac teratogenicity could occur as a result of air pollutant exposure. Potential mechanisms underlying air pollutant-induced teratogenicity have been reported, including chromosome and DNA damage (genotoxicity); oxidative stress; altered levels and/or functions of enzymes, hormones and proteins; apoptosis; and toxicogenomic and epigenomic effects (such as DNA methylation)[34,35]. Some have suggested[36] that maternal exposure to air pollution might influence endothelial function and blood viscosity, which could alter maternal-placental oxygen and nutrient exchanges and thus affect foetal development. More likely, the association that we observed could be attributable to a joint effect of several air pollutants based on various biological mechanisms.

Concentrations of indoor air pollutants display individual variation owing to complex and diverse indoor or outdoor sources, room temperature and humidity, as well as living habits or application of appliances that might reduce or increase the pollutant concentration[27].

TVOCs, consisting of various VOCs such as formaldehyde, trichloroethylene, benzene series, and hydrocarbon compounds, are mainly attributed to indoor sources including building materials, household chemical products, and combustion processes causing smoke[37]. High concentrations of VOCs, which may be emitted from materials such as paints, dyes, adhesives, solvents, boards and plywood, are more often reported in new residential buildings or renovated dwellings[27, 38, 39]. A case-control study in China described that maternal exposure to house renovations increased the risk of CHD, and this relationship was stronger for women who had moved into a newly decorated house[20]. Although there is insufficient evidence of the effects of traditional decorative materials (such as floors, wall decorations and furniture) on CHD risk in our results, we observed a significant TVOC exposure odd for CHDs in newly renovated houses (AOR 32.13, 95Cl: 1.48-698.11) but not in houses without renovation. This finding may suggest that people are prone to using traditional decorative materials that are environmentally friendly but that more new-style or complicated ornaments in newly renovated houses that were not reported in our study may contribute to indoor TVOC pollution. Among subjects in newly renovated houses, it seemed that fewer CHDs occurred in subjects living in houses with more than a 3-month moving-in interval, which may indicate that renovation-related volatile air pollutants are time dependent and decrease over time.

Moreover, outdoor sources resulting from the oil and gas industry, transport emissions and biogenic emissions can affect indoor TVOC concentrations through air exchange[40]. In addition, human activities are considered to be significant sources of indoor air pollution. Natural and mechanical ventilation are indicated to improve the levels of chemical pollutants in indoor air[27, 41]. Second-hand smoke was not associated with CHDs in our study, yet smoke ventilator usage during cooking tended to modify the effect of TVOCs on CHDs and implied that the improvement in indoor air quality might have a positive impact on lowering CHD risks. Traffic-related emissions from the outdoors seemed to not interfere in the effect of indoor TVOC on CHDs but increased the PM-associated risk for $\mathrm{CHDs}$. Although some studies indicated that the levels of indoor $\mathrm{PM}_{2.5}$ resulted from pan-frying in kitchens ${ }^{[42]}$, our study did not show that smoke ventilator usage in cooking could modify the effect of PM on CHDs. The results implied that traffic-related outdoor air pollution could be the major contributor of $\mathrm{PM}_{2.5}$ to the indoor environment, which was consistent with Jung's study[43].

However, in the present study, we could not address the contribution of indoor air pollutants from different sources directly due to their complexities. People's living habits and residential environments also vary individually, affecting the level of exposure to indoor air pollutants. More detailed investigations and comprehensive sampling detections are needed in further studies.

In contrast to a study revealing a negative correlation between indoor TVOC and particulate matter concentrations $\left(\mathrm{PM}_{0.5}\right.$ and $\left.\mathrm{PM}_{1}\right)[27], \mathrm{TVOC}$ concentrations showed no obvious correlations with $\mathrm{PM}_{2.5}$ or $\mathrm{PM}_{10}$ in our study, indicating that they may originate from different sources. Nevertheless, we found that $\mathrm{PM}$ exposure had different associations with TVOCs and CHDs. Compared with coexposure to low levels of TVOC $\left(<0.25 \mathrm{mg} / \mathrm{m}^{3}\right)$ and PM $2.5\left(<13 \mu \mathrm{g} / \mathrm{m}^{3}\right)$, coexposure to high levels of TVOCs $\left(\geq 0.25 \mathrm{mg} / \mathrm{m}^{3}\right)$ and $\mathrm{PM}_{2.5}\left(\geq 13 \mu \mathrm{g} / \mathrm{m}^{3}\right)$ was associated with a 6.77 times higher risk for CHDs. It could be suggested that coexposure to TVOCs and $\mathrm{PM}_{2.5}$ had a certain synergistic effect on $\mathrm{CHD}$ occurrence. An animal experiment suggested that exposure to a combination of $\mathrm{PM}_{2.5}$ and formaldehyde can result in increased lung damage in mice with allergic asthma as a result of oxidative stress, immunogenic response and neurogenic response[44]. The biological mechanisms for the joint effect of indoor air pollutants on foetal cardiac development remain to be further investigated.

Despite constant public concern about indoor air quality, China's national standards, GB/T 18883 - 2002 and GB3095-2012, were put into effect successively and set guideline values for formaldehyde, BTXs, TVOCs, $\mathrm{PM}_{10}$ and $\mathrm{PM}_{2.5}$. However, a specific threshold for susceptible populations, especially pregnant women, is not yet defined in China, probably due to a lack of information on exposure and risk assessment. Our research initially indicated that indoor air pollution was associated with foetal CHDs, yet the exact cut-off value for CHD occurrence still needs to be confirmed in an abundant sample with a sophisticated design. To the best of our knowledge, this study is the first to explore the CHD-related effects of personal maternal air pollution exposure, as 
opposed to data obtained from air quality monitoring stations in many previous studies[8, 11, 18]. Personal measurements are generally considered a more accurate representation of exposure levels.

The main limitation of our study was the small sample size resulting in limited statistical power-the Cls for less common exposures were wide. The problem of insufficient sample size was especially prominent for some subtypes, such as anomalous pulmonary venous return. The real statistical power may be affected by the small samples for the specific subtypes; thus, we mainly demonstrated associations between maternal exposure to indoor air pollution and total CHDs in our study population. Second, air samples were collected from participants at a median of 25 gestational weeks after the critical period for cardiac development that occurs during the first three months of gestation[14], which may have introduced nondifferential misclassification and decreased the accuracy of the exposure assessment. Although the volatility of indoor air pollution may result in low detection values at sampling time and misclassify exposure level for some participants, the collection of data and air samples in this study were based on unaltered lifestyles and immobile living environments, and the results could reflect the relatively quantifiable exposure within the pregnancy period for the case-control design. In addition, our survey timing was much earlier than most previous reports that usually collected personal exposure air samples during the third trimester of pregnancy[31, 45] or even after delivery[46]. Third, more measured indoor and outdoor pollutant concentrations are needed to calculate indoor/outdoor ratios and confirm the source of pollutants. Although we collected prenatal information on sociodemographics, reproductive history and periconceptional health status based on previous literature[3-7] and adjusted the analysis for several covariates, we cannot rule out potential confounding by unmeasured or unknown factors. More detailed investigations and comprehensive sampling detections are needed in further studies. Due to the small sample size, the number of determinants included in the models was restricted; thus, we did not assess the risks in the multipollutant model.

\section{Conclusions}

As increasing evidence suggests that ambient air pollution, which has teratogenic properties, results in a serious threat to humans at birth and, specifically, may increase the risk of CHDs, indoor air quality has become a public health concern in developed eastern China. Our findings indicated adverse effects of TVOCs, $\mathrm{PM}_{2.5}$ and $\mathrm{PM}_{10}$ during pregnancy on the outcome of foetal CHDs, even at low exposure levels. These effects may have been enhanced for pregnant woman living in a newly renovated house or near heavy traffic roads but mitigated by household usage of smoke ventilators when cooking. Our results also suggested a synergistic interaction of maternal exposure to TVOCs and $\mathrm{PM}_{2.5}$ in regard to the risk for CHDs. Our study results may provide useful evidence for developing interventions to improve indoor air quality among pregnant women.

\section{Abbreviations}

CHD: Congenital heart disease; PM: Particulate matter; $\mathrm{PM}_{10}$ : Particulate matter less than 10 microns in diameter; $\mathrm{PM}_{2.5}$ : Particulate matter less than 2.5 microns in diameter; VOCs: Volatile organic compounds; BTX: Benzene, toluene, xylene; TVOCs: Total volatile organic compounds; GC-FID: Gas chromatography with flame ionization detection; MBTH: 3-methyl-2-benzonthiazolinone hydrazine; MDLs: Method detection limits; COR: Crude odds ratio; Cl: Confidence interval; AOR: Adjusted odds ratio; RERI: Relative excess risk due to interaction; AP: Attributable proportion.

\section{Declarations}

\section{Acknowledgements}

We would like to thank all the partners in this study for their help and support.

\section{Authors' contributions}

JS, JW and JY: study conception, study design and coordination, data acquisition, statistical analysis and interpretation, manuscript drafting. PK: study conception, design and coordination, manuscript review and editing. XS: data acquisition. SL: data acquisition. JC: study conception, data acquisition, data validation, and manuscript review \& editing. SC: study coordination, manuscript review \& editing. KS: study conception and design, funding acquisition, data validation, project administration and manuscript review \& editing. YW: study conception and design, project administration and manuscript review \& editing. All authors were engaged with the critical revision of the article for important intellectual content and approved of the final manuscript.

\section{Funding}

This study was supported by funding from a Multi-center Clinical Research Project of Shanghai Jiao Tong University School of Medicine [grant number DLY201609].

\section{Availability of data and materials}

The datasets generated and/or analyzed during the current study are not publicly available due to data privacy issues but are available from the corresponding authors (KS and YW) on reasonable request

\section{Ethics approval and consent to participate}

Ethical approval for the study was obtained in 2016 from the Ethics Committee of Xinhua Hospital (No. XHEC-D-2016-401-2). The investigation conformed with the principles outlined in the 1964 Helsinki Declaration. Only participants who gave voluntary written informed consent to participate in the study were included in the survey. 


\section{Consent for publication}

Not applicable.

\section{Competing interests}

The authors declare they have no actual or potential competing financial interests.

\section{Author details}

a Department of Pediatric Cardiology, Xinhua Hospital, School of Medicine, Shanghai Jiao Tong University, No. 1665 Kongjiang Road, Shanghai 200092, China.

${ }^{b}$ Department of Fetal Echocardiography, Jiaxing Maternity and Child Health Care Hospital, No. 2468 Zhonghuan Dong Road, Jiaxing 314051, China.

c School of environmental science and engineering, Shanghai Jiao Tong University, No. 800 Dongchuan Road, Shanghai 200240, China.

\section{References}

1. Zheleva B, Atwood JB. The invisible child: childhood heart disease in global health. Lancet. 2017;389(10064):16-8.

2. Musa NL, Hjortdal V, Zheleva B, Murni IK, Sano S, Schwartz S, Staveski SL. The global burden of paediatric heart disease. Cardiol Young. 2017;27(S6):38.

3. Xu A, Cao X, Lu Y, Li H, Zhu Q, Chen X, Jiang H, Li X. A Meta-Analysis of the Relationship Between Maternal Folic Acid Supplementation and the Risk of Congenital Heart Defects. International Heart Journal. 2016;57(6):725-8.

4. Best KE, Rankin J. Is advanced maternal age a risk factor for congenital heart disease? Birth Defects Research Part A Clinical Molecular Teratology. 2016;106(6):461-7.

5. Agha MM, Glazier RH, Moineddin R, Moore AM, Guttmann A: Socioeconomic status and prevalence of congenital heart defects: Does universal access to health care system eliminate the gap? Birth Defects Research Part A Clinical \& Molecular Teratology 2011, 91(12):1011-1018.

6. Parnell AS, Correa A, Reece EA. Pre-pregnancy Obesity as a Modifier of Gestational Diabetes and Birth Defects Associations: A Systematic Review. Maternal Child Health Journal. 2017;21(5):1105-20.

7. Hackshaw A, Rodeck C: Maternal smoking in pregnancy and birth defects: a systematic review based on 173687 malformed cases and 11.7 million controls. Human Reproduction Update 2011, 17(5):589-604.

8. Dolk H, Armstrong B, Lachowycz K, Vrijheid M, Rankin J, Abramsky L, Boyd PA, Wellesley D. Ambient air pollution and risk of congenital anomalies in England, 1991-1999. Occupational \& Environmental Medicine 2010, 67(4):223-227.

9. Gilboa SM, Mendola P, Olshan AF, Langlois PH, Savitz DA, Loomis D, Herring AH, Fixler DE. Relation between ambient air quality and selected birth defects, seven county study, Texas, 1997-2000. American Journal of Epidemiology 2005(3):238.

10. Hansen CA, Barnett AG, Jalaludin BB, Morgan GG, Pan X. Ambient Air Pollution and Birth Defects in Brisbane, Australia. Plos One. 2009;4(4):e5408-

11. Strickland MJ, Klein M, Correa A, Reller MD, Mahle WT, Riehle-Colarusso TJ, Botto LD, Flanders WD, Mulholland JA, Siffel C, et al. Ambient air pollution and cardiovascular malformations in Atlanta, Georgia, 1986-2003. Am J Epidemiol. 2009;169(8):1004-14.

12. Brauner EV, Forchhammer L, Moller P, Barregard L, Gunnarsen L, Afshari A, Wahlin P, Glasius M, Dragsted LO, Basu S, et al. Indoor particles affect vascular function in the aged: an air filtration-based intervention study. Am J Respir Crit Care Med. 2008;177(4):419-25.

13. Sousa SI, Ferraz C, Alvim-Ferraz MC, Vaz LG, Marques AJ, Martins FG. Indoor air pollution on nurseries and primary schools: impact on childhood asthma-study protocol. BMC Public Health. 2012;12:435.

14. Hoek G, Brunekreef B, Goldbohm S, Fischer P, van den Brandt PA. Association between mortality and indicators of traffic-related air pollution in the Netherlands: a cohort study. Lancet. 2002;360(9341):1203-9.

15. Weschler CJ. Chemistry in indoor environments: 20 years of research. Indoor Air. 2011;21(3):205-18.

16. Morawska L, Afshari A, Bae GN, Buonanno G, Chao CYH, H?Nninen O, Hofmann W, Isaxon C, Jayaratne ER, Pasanen P. Indoor aerosols: from personal exposure to risk assessment. Indoor Air 2013, 23(6).

17. Collins JJ, Ness R, Tyl RW, Krivanek N, Hall TA. A review of adverse pregnancy outcomes and formaldehyde exposure in human and animal studies. Regulatory Toxicology Pharmacology. 2001;34(1):17-34.

18. Hwang BF, Lee YL, Jaakkola JJ. Air Pollution and the Risk of Cardiac Defects: A Population-Based Case-Control Study. Med (Baltim). $2015 ; 94(44):$ e1883.

19. Wang L, Pinkerton KE. Air pollutant effects on fetal and early postnatal development. Birth Defects Research Part C Embryo Today Reviews 2007.

20. Liu Z, Li X, Li N, Li S, Zhu J. Association between maternal exposure to housing renovation and offspring with congenital heart disease: a multi-hospital case-control study. Environ Health. 2013;12(1):25-5.

21. Liqing Z, Yurong W, Sun C, Yunyun R, Ping C, Jianmei N, Cao L, Kun S, Fatima C. Feasibility Study on Prenatal Cardiac Screening Using Four-Dimensional Ultrasound with Spatiotemporal Image Correlation: A Multicenter Study. Plos One. 2016;11(6):e0157477.

22. Botto L, Lin A, Riehle-Colarusso T, Malik S, Correa A. Seeking causes: Classifying and evaluating congenital heart defects in etiologic studies. Birth defects research Part A Clinical molecular teratology. 2007;79(10):714-27.

23. Li R, Chambless L. Test for Additive Interaction in Proportional Hazards Models. Ann Epidemiol. 2007;17(3):227-36. 
24. Andersson T, Alfredsson L, Kallberg H, Zdravkovic S, Ahlbom A. Calculating measures of biological interaction. Eur J Epidemiol. 2005;20(7):575-9.

25. Vanderweele TJ, Vansteelandt S, Robins JM. Marginal structural models for sufficient cause interactions. Am J Epidemiol. 2010;171(4):506-14.

26. Liu X, Yan M, Duan H. Characteristics of Indoor Volatile Organic Compounds in Urban Residential Microenvironments in China. Res Environ Sci. 2012;25(10):1077-84.

27. Meciarova L, Vilcekova S, Burdova EK, Kiselak J. Factors Effecting the Total Volatile Organic Compound (TVOC) Concentrations in Slovak Households. Int J Environ Res Public Health 2017, 14(12).

28. Kadir MM, Mcclure EM, Goudar SS, Garces AL, Moore J, Onyamboko M, Kaseba C, Althabe F, Castilla EE, Freire S. Exposure of pregnant women to indoor air pollution: a study from nine low and middle income countries. Acta Obstetricia Et Gynecologica Scandinavica. 2011;89(4):540-8.

29. Brautbar N, John Williams II. Industrial solvents and liver toxicity: Risk assessment, risk factors and mechanisms. Int J Hyg Environ Health. 2002;205(6):479-91.

30. Yauck JS, Malloy ME, Blair K, Simpson PM, Mccarver DG. Proximity of residence to trichloroethylene-emitting sites and increased risk of offspring congenital heart defects among older women. Birth Defects Research Part A Clinical Molecular Teratology. 2004;70(10):808.

31. Chang M, Park H, Ha M, Hong YC, Lim YH, Kim Y, Kim YJ, Lee D, Ha EH. The effect of prenatal TVOC exposure on birth and infantile weight: the Mothers and Children's Environmental Health study. Pediatr Res. 2017;82(3):423-8.

32. Navidi W, Lurmann F. Measurement error in air pollution exposure assessment. J Expo Anal Environ Epidemiol. 1995;5(2):111-24.

33. Zhang ZF, Zhang X, Zhang XM, Liu LY, Li YF, Sun W. Indoor occurrence and health risk of formaldehyde, toluene, xylene and total volatile organic compounds derived from an extensive monitoring campaign in Harbin, a megacity of China. Chemosphere. 2020;250:126324.

34. Duong A, Steinmaus C, Mchale CM, Vaughan CP, Zhang L. Reproductive and developmental toxicity of formaldehyde: a systematic review. Mutation Research-Reviews in Mutation Research. 2011;728(3):118-38.

35. Janssen BG, Munters E, Pieters N, Smeets K, Cox B, Cuypers A, Fierens F, Penders J, Vangronsveld J, Gyselaers W, et al. Placental Mitochondrial DNA Content and Particulate Air Pollution during in Utero Life. Environ Health Perspect. 2012;120(9):1346-52.

36. Erickson AC, Arbour L. The Shared Pathoetiological Effects of Particulate Air Pollution and the Social Environment on Fetal-Placental Development. J Environ Public Health. 2014;2014:901017.

37. Guo H. Source apportionment of volatile organic compounds in Hong Kong homes. Building Environment. 2011;46(11):2280-6.

38. Park JS, Ikeda K. Variations of formaldehyde and VOC levels during 3 years in new and older homes. Indoor Air. 2006;16(2):129-35.

39. Brown SK. Volatile Organic Pollutants in New and Established Buildings in Melbourne, Australia. Indoor Air. 2002;12(1):55-63.

40. Bari MA, Kindzierski WB, Wheeler AJ, Heroux M-E, Wallace LA. Source apportionment of indoor and outdoor volatile organic compounds at homes in Edmonton, Canada. Building Environment. 2015;90(aug.):114-24.

41. Lin L-Y, Chuang H-C, Liu IJ, Chen H-W, Chuang K-J. Reducing indoor air pollution by air conditioning is associated with improvements in cardiovascular health among the general population. Science of The Total Environment. 2013;463-464:176-81.

42. Singh A, Kesavachandran CN, Kamal R, Bihari V, Ansari A, Azeez PA, Saxena PN, Anil Kumar KS, Khan AH. Indoor air pollution and its association with poor lung function, microalbuminuria and variations in blood pressure among kitchen workers in India: a cross-sectional study. Environmental Health 2017.

43. Jung C-C, Su H-J, Liang H-H. Association between indoor air pollutant exposure and blood pressure and heart rate in subjects according to body mass index. Science of The Total Environment. 2016;539:271-6.

44. Song J, Kang J, Lin B, Li J, Zhu Y, Du J, Yang X, Xi Z, Li R. Mediating Role of TRPV1 lon Channels in the Co-exposure to PM2.5 and Formaldehyde of Balb/c Mice Asthma Model. Scientific reports. 2017;7(1):11926.

45. Slama R, Thiebaugeorges O, Goua V, Aussel L, Sacco P, Bohet A, Forhan A, Ducot B, Annesi-Maesano I, Heinrich J, et al. Maternal personal exposure to airborne benzene and intrauterine growth. Environmental health perspectives. 2009;117(8):1313-21.

46. Madureira J, Slezakova K, Costa C, Pereira MC, Teixeira JP. Assessment of indoor air exposure among newborns and their mothers: Levels and sources of PM10, PM2.5 and ultrafine particles at 65 home environments. Environmental pollution. 2020;264:114746.

\section{Figures}




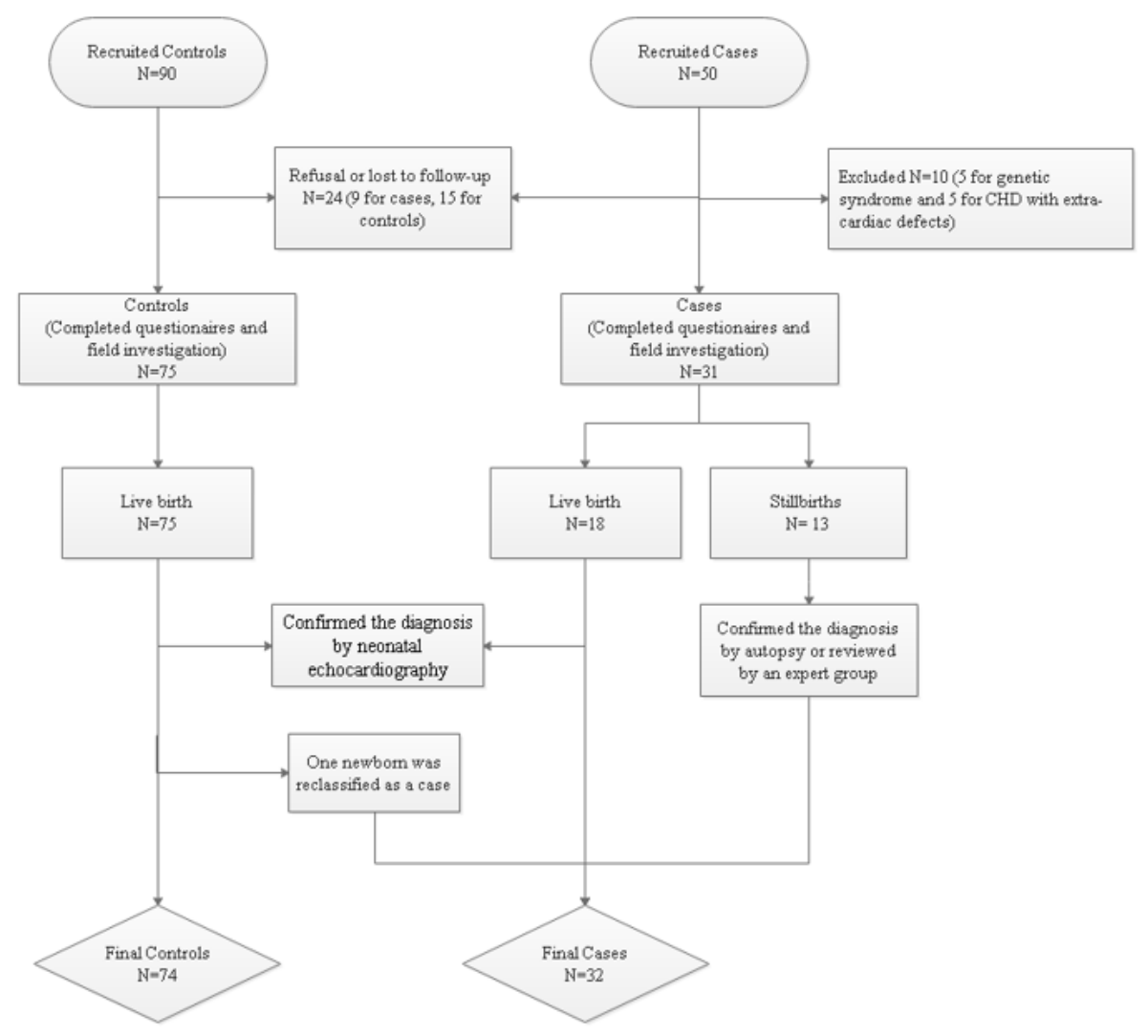

Figure 1

The flow chart of study population recruitment

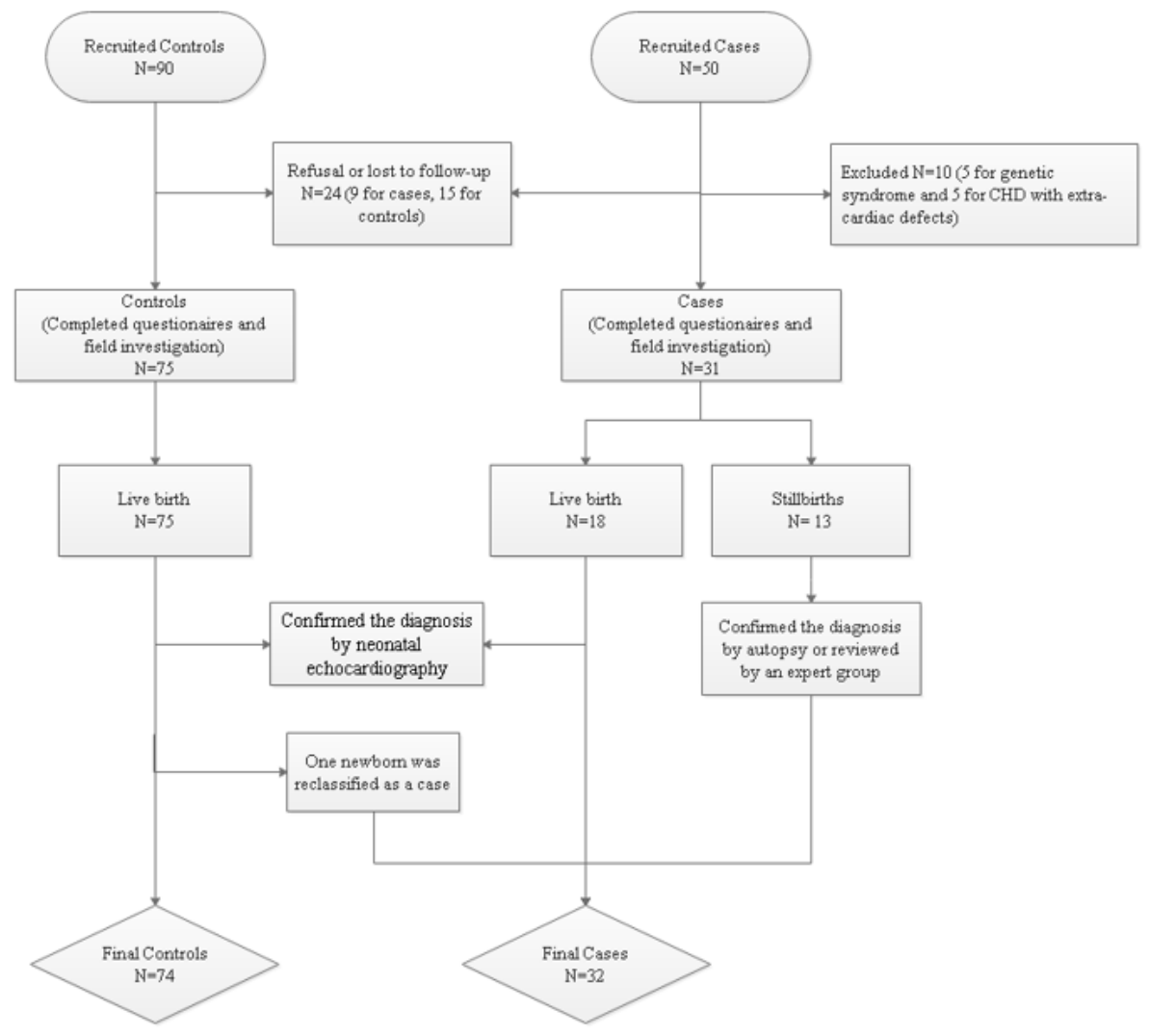

Figure 1

The flow chart of study population recruitment 